\title{
Effects of Telemetry Transmitter Placement on Egg Retention in Naturally Spawning, Captively Reared Steelhead
}

\author{
BARRY A. BEREJIKIAN* \\ National Oceanic and Atmospheric Administration Fisheries, Northwest Fisheries Science Center, \\ Resource Enhancement and Utilization Technologies Division, Manchester Research Station, \\ Post Office Box 130, Manchester, Washington 98353, USA \\ RICHARD S. BROWN \\ Battelle Pacific Northwest Division, Ecology Group, MSIN K6-85, \\ 902 Battelle Boulevard, Post Office Box 999, Richland, Washington 99352, USA

\section{Christopher P. TAtara} \\ National Oceanic and Atmospheric Administration Fisheries, Northwest Fisheries Science Center, \\ Resource Enhancement and Utilization Technologies Division, Manchester Research Station, \\ Post Office Box 130, Manchester, Washington 98353, USA \\ Steven J. Cooke \\ Department of Biology, Carleton University, 1125 Colonel By Drive, Ottawa, Ontario K1S 5B6, Canada
}

\begin{abstract}
Maturing female anadromous salmonids receiving intraperitoneally implanted telemetry transmitters (tags) may experience difficulty depositing eggs during natural spawning. We allocated maturing adult female steelhead Oncorhynchus mykiss to three treatment groups: (1) fish whose tags were surgically implanted in the body cavity (internal), (2) fish whose tags were implanted between the skin and muscle tissue (subdermal), and (3) nontagged fish. The steelhead were then allowed to spawn in an experimental channel. Internally tagged females retained significantly more eggs than did the subdermally tagged and nontagged control groups; subdermally tagged and nontagged control fish did not differ significantly. Females in the internally tagged, subdermally tagged, and nontagged groups retained an average of 49 , 11 , and $2 \%$ of their eggs, respectively. The onset of sexual activity did not differ significantly among treatments. Postspawning mortality was $70 \%$ for internally and subdermally tagged females and $0 \%$ for nontagged females. Each research or monitoring program should weigh the costs associated with transmitter use (where they are known) against the value of information obtained and should carefully evaluate assumptions about transmitter effects. For these reasons, the use of electromyogram electrodes and other telemetry transmitters for monitoring imperiled fish populations should be employed with caution. We suggest that subdermal implantation techniques be considered in future studies during the reproductive period to reduce egg retention caused by internally implanted transmitters.
\end{abstract}

Innovations in biotelemetry provide researchers with new tools for assessing the behavior and physiology of

\footnotetext{
* Corresponding author: barry.berejikian@noaa.gov
}

Received May 12, 2006; accepted October 4, 2006 Published online May 3, 2007 free-swimming fish (Cooke et al. 2004a). This is particularly true for the reproductive period, which is typically a stressful and important time in the life history of fish and consequently one that requires study to facilitate management and conservation. Studies using positional telemetry have provided much-needed information on migration speeds (Keefer et al. 2004; English et al. 2005) and migration failure rates (English et al. 2005). More recent research using sensors such as electromyogram (EMG) electrodes (see EMG telemetry review by Cooke et al. 2004b) or thermistors enable researchers to also quantify migration energetics (Hinch and Rand 1998; Geist et al. 2000, 2003; Standen et al. 2002), detailed migratory behavior (Hinch et al. 1996, 2002; Hinch and Bratty 2000; Brown et al. 2006), thermal ecology (Newell and Quinn 2005), and spawning dynamics (Cooke et al. 2001; Healey et al. 2003). To date, these findings have led to the development of energetics models, refinement in harvest strategies, and a better understanding of the influence of environmental characteristics on reproduction.

Although significant advances in telemetry technology have led to smaller transmitters or archival loggers, some devices, especially those equipped with sensors, are still reasonably large (e.g., tags in the present study were $11.9 \mathrm{~g}$ ). Accordingly, questions about their associated effects on the behavior, physiology, and health of the tagged individuals remain (Bridger and Booth 2003). Telemetry devices are commonly implanted in the intraperitoneal cavity of the fish (Mulcahy 2003; Cooke et al. 2004a). When so 
equipped, the external radio antenna extends posteriorly through the body wall. Some devices such as EMG transmitters also involve the placement of electrodes in the red musculature just beneath the lateral line (see Cooke et al. 2004b for details). Telemetry transmitters or implantation techniques may present unique problems when the technology is applied to studying behavior (e.g., courtship, intersexual and intrasexual competition, parental care) and energetics during reproduction (Cooke et al. 2001; Healey et al. 2003). For example, B. A. Berejikian et al. (in press) found significantly higher egg retention and lower adult-to-fry reproductive success in Chinook salmon Oncorhynchus tshawytscha implanted intraperitoneally with EMG transmitters during natural spawning relative to those variables in control fish in two separate experiments. Water intrusion during the tagging procedure could cause eggs to water harden before spawning; also, the presence of the tag could affect muscle contraction or impede the movement of eggs during spawning. The EMG transmitters in those studies were implanted internally, and it was hypothesized that water intrusion and loss of ovarian fluid from the body cavity hindered egg deposition. In a study of energy expenditure in sockeye salmon $O$. nerka during reproduction, Healey et al. (2003) used both internal and subdermal implantation methods; the latter method was applied to eliminate water intrusion into the body cavity. Other researchers have attempted to use oviduct insertion techniques (e.g., Peake et al. 1997), but those studies are limited in duration and are not suitable for most sensor devices.

We tested two transmitter implantation techniques (intraperitoneal and subdermal) and quantified the effects on reproductive life span and egg retention using captively reared steelhead $O$. mykiss from a common population. We allocated maturing adult females to three treatments-internally tagged, subdermally tagged, and nontagged-and allowed them to spawn in an experimental spawning channel. Although our assessment involved the implantation of EMG transmitters, these findings should be equally applicable to other radio, acoustic, or archival devices of similar size and configuration.

\section{Methods}

Steelhead used for the experiment were offspring of the Skookumchuck River hatchery (Thurston County, Washington) population produced from single-pair matings in 2002. The fish were reared in hatchery tanks (described in Riley et al. 2005) until age 1, when they underwent smoltification and were transferred to a common seawater tank at the National Marine Fisheries Service's Manchester Research Station
(MRS) in Manchester, Washington. The fish were fed ad libitum until sexual maturity. Thirty maturing age-3 steelhead females and 20 maturing males were used in the experiment. Ten females were allocated to each of three treatments such that the mean fork length $( \pm S E)$ of fish in the three treatments did not differ by more than $2.3 \%$ (internally tagged group: $422 \pm 36 \mathrm{~mm}$; subdermally tagged group: $432 \pm 26 \mathrm{~mm}$; nontagged group: $427 \pm 32 \mathrm{~mm}$ ).

On 2 March 2005, each female to receive a tag (6.1 $\mathrm{cm}$ long $\times 1.1 \mathrm{~cm}$ in diameter, $11.9 \mathrm{~g}$ ) was anesthetized with tricaine methanesulfonate (80-100 mg/L), weighed, measured, and placed on a tagging cradle. A flow of oxygenated water containing a $40-\mathrm{mg} / \mathrm{L}$ concentration anesthetic irrigated the gills throughout the tagging procedures. The internal tagging procedures were similar to those used by Hinch et al. (1996) and Geist et al. (2003) and involved placing the tag into the peritoneum through a $3-\mathrm{cm}$ incision and closing the incision with four sutures (Ethicon 2-0 braided silk). Transmitters were disinfected by placing them in $70 \%$ ethanol for $20 \mathrm{~min}$. The subdermal tagging procedure involved a $3-\mathrm{cm}$ incision along the left side of the body directly below the dorsal fin and between the lateral line and midline of the belly. The skin tissue was separated from the muscle tissue in an area similar to the size of the tag using the blunt end of a scalpel handle. The tag was placed into this "pocket," and the two polyvinyl-coated, steel-wire electrodes with gold tips were secured in the red musculature just under the surface of the skin beneath the lateral line. The incision was closed with three or four $2-0$ silk sutures, and triple antibiotic ointment was applied to the surface of the closed incision to prevent infection. The electrode wires extended between the skin and muscle tissue and terminated in the red musculature just beneath the lateral line. The antenna extended between the skin and muscle tissue and exited the skin approximately $3 \mathrm{~cm}$ from the posterior end of the tag. Every female, including those not receiving EMG tags, was also fitted with a 3-cm-diameter, individually numbered Petersen disc tag in the dorsal musculature for visual identification. Exactly $60 \%$ of the females within each treatment were ovulated at the time of tagging.

All 30 females and 20 males were stocked into a spawning channel ( $40 \mathrm{~m}$ long $\times 6 \mathrm{~m}$ wide $)$ at the MRS on 3 March 2005. The channel was configured to create a meandering flow pattern with variable water depths and velocities (see description in Berejikian et al. 2003). All fish had access to the entire channel $\left(240 \mathrm{~m}^{2}\right.$ of available spawning area; flow $=4,800 \mathrm{~L}$ / $\mathrm{min}$ ), which was visually scanned three times per day between 3 and 22 March (except for 5-6 and 12-13 March) to determine which females were sexually 


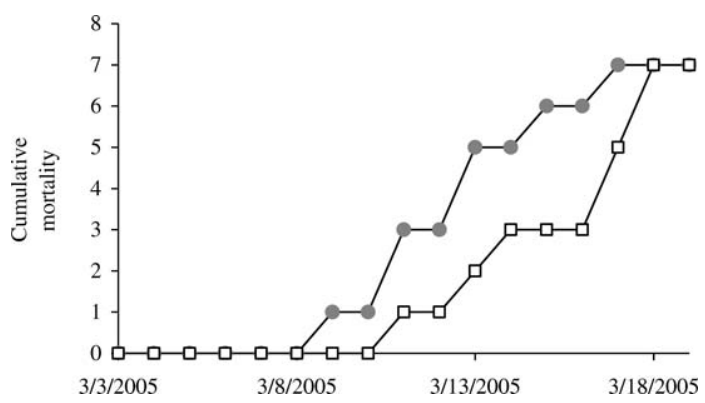

FIGURE 1.-Cumulative mortality of subdermally tagged (open squares; $n=10$ ) and internally tagged (filled circles; $n=$ 10) female steelhead held in an experimental spawning channel at the Manchester Research Station, Manchester, Washington. Nontagged females used as control fish exhibited no mortality and therefore are not shown.

active. Sexually active females were defined as those in the process of nest construction (i.e., digging) or observed to be holding position over a nest depression while being courted by a male. Dead females were removed and dissected, and any loose eggs retained were counted. All females, alive or dead, were removed on 22 March, by which time no females remained sexually active.

Females allocated to the three tag treatments were assumed to have equal mean fecundity, because they had been reared in a common tank and were of similar size. Therefore, the number of eggs retained at death should reflect an unbiased estimate of the proportion of eggs retained. The mean number of eggs retained, time to onset of sexual activity, and postrelease life span were compared among treatments by one-way Kruskal-Wallis tests $(\alpha=0.05)$. Mann-Whitney tests were used to make pairwise comparisons. The experimentwise error rate for the pairwise comparisons was set at 0.05 by recalculating the critical $U$-value $\left(U_{0.05}=\right.$ 80.96; $\mathrm{df}=3,10$ ) to account for multiple testing (Sokal and Rohlf 1996).

\section{Results}

Some females began constructing nests within a few hours of being placed in the spawning channel. The mean onset of sexual activity did not differ significantly among treatments $(H=1.78, \mathrm{df}=2, P=0.413)$. No females remained sexually active after $15 \mathrm{~d}$ poststocking. Mortality as of $19 \mathrm{~d}$ poststocking (when all fish were removed) was $70 \%$ for both internally and subdermally tagged females and $0 \%$ for nontagged females $(H=20.81$, df $=2, P<0.01$; Figure 1$)$. Although the time until death for internally tagged fish was slightly advanced compared with the subdermally tagged fish (Figure 1), multiple comparison tests

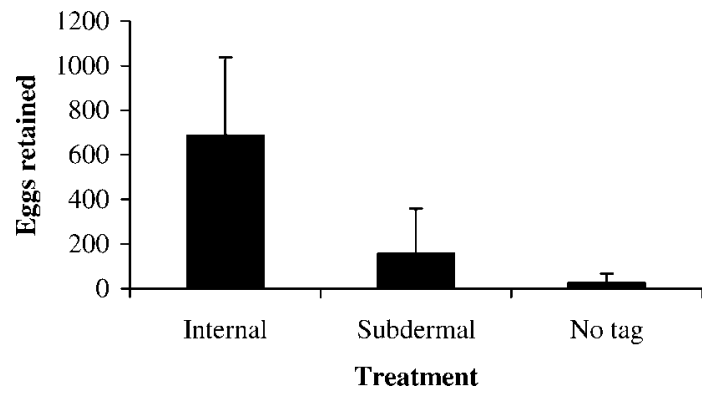

FiguRE 2.-Mean ( \pm 2 SE) number of eggs retained by subdermally tagged $(n=10)$, internally tagged $(n=10)$, and nontagged $(n=10)$ female steelhead held in an experimental spawning channel at the Manchester Research Station, Manchester, Washington.

showed that the two groups did not differ significantly $(U=36.5, \mathrm{df}=1, P=0.299)$.

The treatments differed significantly in the number of eggs retained at death $(H=13.75, \mathrm{df}=2, P<$ $0.001)$. Internally tagged females retained more eggs than did the subdermally tagged $(P=0.005)$ and nontagged $(P=0.001)$ females; the subdermally tagged and nontagged groups did not differ significantly $(P=$ 0.934; Figure 2).

We conducted a post hoc analysis of covariance (ANCOVA) to separate the effects of longevity (time until death) from the tagging method (internal versus subdermal). The nontagged treatment was not included because no fish died and very few eggs were retained. Longevity was negatively correlated with egg retention $\left(F_{1,17}=27.18, P<0.001\right)$. However, internally tagged females retained a significantly greater number of eggs than did subdermally tagged females after the variability associated with longevity was removed from the ANCOVA model $\left(F_{1,17}=7.52, P<0.014\right.$; Figure 3$)$.

Two internally tagged females were the only fish never observed to be sexually active; they died early (6 and $8 \mathrm{~d}$ poststocking) and retained more eggs $(1,315$ and 1,496$)$ than any other female. Thus, we assume that these females did not spawn and their egg retention reflects their actual fecundity. The two females were near the average size for each of the three treatment groups, so their mean fecundity (1,406 eggs) was used to provide an estimate of the mean fecundity of each group. Based on the fecundity estimate, the internally tagged, subdermally tagged, and nontagged groups retained an average of 49,11 , and $2 \%$ of their eggs, respectively.

\section{Discussion}

Application of positional and EMG telemetry has broadened to include assessments of reproductive 


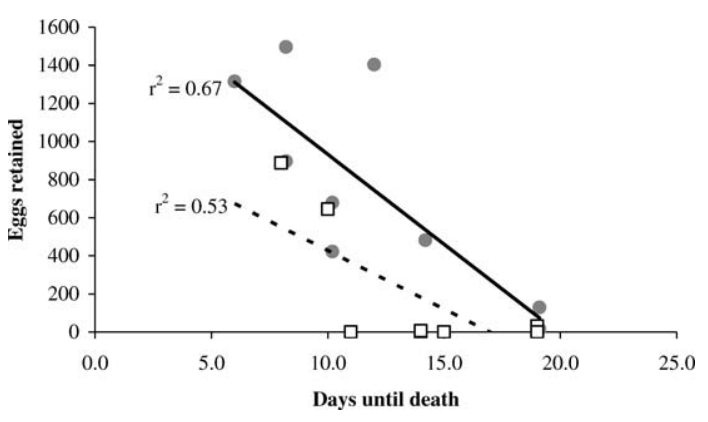

FIGURE 3.-Relationship between time until death (d) and number of eggs retained by individual subdermally tagged (open squares; dashed line) and internally tagged (solid circles; solid line) female steelhead held in an experimental spawning channel at the Manchester Research Station, Manchester, Washington. Regression slopes and $r^{2}$ values are shown separately for each treatment (see text for ANCOVA results).

activity (Kaseloo et al. 1996; Økland et al. 2000; Cooke et al. 2001; Healey et al. 2003; Berejikian et al., in press). To obtain accurate, representative results, tagging must be done in a way that does not compromise behavior or reproductive success. The latter is of greater importance when innovative tagging and evaluation techniques are used on imperiled populations that require intensive monitoring. The use of EMG telemetry to detect individual spawning events and thereby determine spawn timing and frequency (Berejikian et al., in press) is particularly suitable for populations that are supplemented with artificially propagated fish spawning in discrete areas (e.g., Redfish Lake sockeye salmon: Hebdon et al. 2004; Hamma Hamma River steelhead: Kuligowski et al. 2005).

The subdermal tagging method significantly reduced egg retention relative to that of the conventional, intraperitoneal tagging method. Premature mortality appeared to contribute to egg retention in females from both tag treatments. Nevertheless, subdermal tagging reduced egg retention relative to that of internal tagging when the effects of longevity were considered. The majority of females in both treatments were observed constructing nests, attempting to deposit eggs, and behaving otherwise similarly to the nontagged fish. Thus, internally tagged females apparently had greater difficulty than subdermally tagged females in expelling eggs from the body cavity during spawning. The reduced egg deposition by internally tagged steelhead is consistent with results of Berejikian et al. (in press), in which (1) the spawning frequency and longevity of internally tagged and nontagged Chinook salmon were similar but (2) egg retention was significantly higher in tagged fish than in nontagged fish.

The conclusions of the study with respect to comparing the three treatments are based on the number of eggs retained and an assumption of equal fecundity among treatments. All steelhead used in this experiment were reared in a common tank, and the body sizes of fish (ranges and means) allocated to the three treatments from the rearing tank were very similar. The mean fecundity estimate, based on only two individuals, provided a reference for estimating the proportion of eggs deposited by females from the three treatments. If actual mean fecundity was less than the estimate, then egg deposition would be lower than reported, and the reverse would be true if actual mean fecundity was greater than the estimate. Regardless, the among-treatment comparison of the effects of the transmitters and their placement are not biased by the fecundity estimate.

Necropsies of females from each treatment group indicated that poorer egg deposition in the internally tagged group may have been caused by water intrusion into the body cavity through the incision and loss of ovarian fluid. Water could readily permeate the incision, and internally tagged females often contained water-hardened eggs. The role of ovarian fluid in facilitating egg deposition is unclear, but ovarian fluid may serve as a lubricant or to maintain hydrostatic pressure in the body cavity, both of which may be necessary for egg deposition. The two electrode wires present in the body cavity of internally tagged females could have impeded egg deposition, but the majority of retained ovulated eggs were posterior of the electrode wires and were in contact with the vent.

Based on the results of this study, we recommend the subdermal tagging technique over the internal technique for reproductively maturing salmonids. However, subdermal tagging did shorten the reproductive life span, which would reduce the reproductive potential of iteroparous fish populations tagged and released in natural streams. The magnitude of the effect on a tagged group of fish would depend on the probability of repeat spawning (see Quinn 2005 for an overview of iteroparity in steelhead). In semelparous salmonids, reduced longevity could impair the ability of females to cover redds with additional gravel after spawning and could reduce their ability to guard redds from superimposition from later-spawning females (McPhee and Quinn 1998). It is also possible that the reduced longevity of the internally and subdermally tagged steelhead we observed may not occur in fish that are substantially larger than those used here. Berejikian et al. (in press) found no effect of internally implanted tags on longevity in Chinook salmon in two 
consecutive years. The tag weight as a percentage of fish body weight ranged between $0.1 \%$ and $0.3 \%$ in that study, but the range was $0.8-1.8 \%$ in the present study. The causes of reduced longevity in the subdermally implanted fish are unclear. We did not observe any bleeding during the surgeries, and necropsies did not reveal any damage to internal organs. Physiological stress related to the tagging procedure itself or the presence of the tag during spawning may have contributed to reduced longevity.

As with any laboratory experiment, the results from this stream channel experiment may overestimate or underestimate transmitter effects that might exist for wild-spawning fish. Each research or monitoring program should weigh the costs associated with transmitter use (where they are known) against the value of information obtained and should carefully evaluate assumptions regarding transmitter effects. For these reasons, use of EMG and other telemetry transmitters for monitoring imperiled fish populations should be conducted with caution.

Relative to internal implantation, subdermal implantation of EMG transmitters appears to increase the likelihood that adult salmonids will spawn in a manner similar to that of untagged fish. As such, this technique provides a novel means of reducing egg retention or changes in gamete quality that can result from intraperitoneal implantation of transmitters. Subdermal implantation can lead to pressure-induced necrosis after longer deployments (S.J.C., personal observation) and may best suit semelparous fish during the later stages of migration or immediately before or during spawning.

\section{Acknowledgments}

We thank Skip Tezak (National Marine Fisheries Service) and John Stephenson and Abby Capetillo (Battelle) for their assistance with set-up of the experimental facilities and fish tagging. Tom Flagg (National Marine Fisheries Service) provided valuable comments on earlier drafts of the manuscript. Rosalind Schrempf provided editing. Animal facilities were certified by the Association for Assessment and Accreditation of Laboratory Animal Care; animals were handled in accordance with federal guidelines for the care and use of laboratory animals, and protocols were approved by the Battelle Pacific Northwest Division Institutional Animal Care and Use Committee. This research was funded by the Bonneville Power Administration.

\section{References}

Berejikian, B. A., R. Endicott, D. VanDoornik, R. S. Brown, C. P. Tatara, and J. J. Atkins. In press. Spawning by female
Chinook salmon can be detected by electromyogram. Transactions of the American Fisheries Society 136.

Berejikian, B. A., W. T. Fairgrieve, P. Swanson, and E. P. Tezak. 2003. Current velocity and injection of GnRHa affect reproductive behavior and body composition of captively reared Chinook salmon (Oncorhynchus tshawytscha). Canadian Journal of Fisheries and Aquatic Sciences 60:690-699.

Bridger, C. J., and R. K. Booth. 2003. The effects of biotelemetry transmitter presence and attachment procedures on fish physiology and behavior. Reviews in Fisheries Science 11:13-34.

Brown, R. S., D. R. Geist, and M. G. Mesa. 2006. The use of electromyogram (EMG) telemetry to assess swimming activity of adult spring Chinook salmon migrating past a Columbia River dam. Transactions of the American Fisheries Society 135:281-287.

Cooke, S. J., S. G. Hinch, M. Wikelski, R. D. Andrews, T. G. Wolcott, and P. J. Butler. 2004a. Biotelemetry: a mechanistic approach to ecology. Trends in Ecology and Evolution 19:334-343.

Cooke, S. J., R. S. McKinley, and D. P. Philipp. 2001. Physical activity and behavior of a centrarchid fish, Micropterus salmoides (Lacepede), during spawning. Ecology of Freshwater Fish 4:227-237.

Cooke, S. J., E. B. Thorstad, and S. G. Hinch. 2004b. Activity and energetics of free-swimming fish: insights from electromyogram telemetry. Fish and Fisheries 5:21-52.

English, K. K., W. R. Koski, C. Sliwinski, A. Blakley, A. Cass, and J. C. Woodey. 2005. Migration timing and river survival of late-run Fraser River sockeye salmon estimated using radiotelemetry techniques. Transactions of the American Fisheries Society 134:1342-1365.

Geist, D. R., C. S. Abernathy, and S. L. Blanton. 2000. The use of electromyogram telemetry to estimate energy expenditure of adult fall Chinook salmon. Transactions of the American Fisheries Society 129:126-135.

Geist, D. R., R. S. Brown, V. I. Cullinan, M. G. Mesa, S. P. Vanderkooi, and C. A. Mckinstry. 2003. Relationships between metabolic rate, muscle electromyograms and swim performance of adult Chinook salmon. Journal of Fish Biology 63:970-989.

Healey, M. C., R. Lake, and S. G. Hinch. 2003. Energy expenditures during reproduction by sockeye salmon (Oncorhynchus nerka). Behaviour 140:161-182.

Hebdon, L. J., P. Kline, D. Taki, and T. A. Flagg. 2004. Evaluating reintroduction strategies for Redfish Lake sockeye salmon captive broodstock progeny. Pages 99103 in M. J. Nickum, P. M. Mazik, J. G. Nickum, and D. D. MacKinlay, editors. Propagated fish in resource management. American Fisheries Society, Symposium 44, Bethesda, Maryland.

Hinch, S. G., and J. Bratty. 2000. Effects of swim speed and activity pattern on success of adult sockeye salmon migration through an area of difficult passage. Transactions of the American Fisheries Society 129:598-606.

Hinch, S. G., R. E. Diewert, T. J. Lissimore, M. J. Prince, M. C. Healey, and M. A. Henderson. 1996. Use of electromyogram telemetry to assess difficult passage areas for river-migrating adult sockeye salmon. Transactions of the American Fisheries Society 125:253-260.

Hinch, S. G., and P. S. Rand. 1998. Swim speeds and energy 
use of upriver-migrating sockeye salmon (Oncorhynchus nerka): role of local environment and fish characteristics. Canadian Journal of Fisheries and Aquatic Sciences 55:1821-1831.

Hinch, S. G., E. M. Standen, M. C. Healey, and A. P. Farrell. 2002. Swimming patterns and behaviour of uprivermigrating adult pink (Oncorhynchus gorbuscha) and sockeye $(O$. nerka $)$ salmon as assessed by EMG telemetry in the Fraser River, British Columbia, Canada. Hydrobiologia 483:147-160.

Kaseloo, P. A., A. H. Weatherley, P. E. Ihssen, D. A. Anstey, and M. D. Gare. 1996. Electromyograms from radiotelemetry as indicators of reproductive activity in lake trout. Journal of Fish Biology 48:664-674.

Keefer, M. L., C. A. Peery, M. A. Jepson, and L. C. Stuehrenberg. 2004. Upstream migration rates of radiotagged adult Chinook salmon in riverine habitats of the Columbia River basin. Journal of Fish Biology 65:1-16.

Kuligowski, D. R., M. J. Ford, and B. A. Berejikian. 2005. Fine-scale patterns of genetic relatedness in a population of steelhead (Oncorhynchus mykiss). Transactions of the American Fisheries Society 134:1202-1212.

McPhee, M. V., and T. P. Quinn. 1998. Factors affecting the duration of nest defense and reproductive lifespan of female sockeye salmon, Oncorhynchus nerka. Environmental Biology of Fishes 51:369-375.

Mulcahy, D. M. 2003. Surgical implantation of transmitters into fish. Institute for Laboratory Animal Research Journal 44:295-306.

Newell, J. C., and T. P. Quinn. 2005. Behavioral thermoreg- ulation by maturing adult sockeye salmon (Oncorhynchus nerka) in a stratified lake prior to spawning. Canadian Journal of Zoology 83:1232-1239.

Økland, F., I. A. Flemming, E. B. Thorstad, B. Finstad, S. Einum, and R. S. McKinley. 2000. EMG telemetry to record the intensity of swimming- and breeding-related behaviour in Atlantic salmon. Pages 51-58 in A. Moore and I. Russell, editors. Advances in fish telemetry. Proceedings of the third conference on fish telemetry in Europe. Centre for Environment, Fisheries and Aquaculture Science, Lowestoft, UK.

Peake, S., R. S. McKinley, T. Beddow, and G. Marmula. 1997. A new procedure for radio transmitter attachment: oviduct insertion. North American Journal of Fisheries Management 17:757-762.

Quinn, T. P. 2005. The behavior and ecology of Pacific salmon and trout. University of Washington Press, Seattle.

Riley, S. C., C. P. Tatara, and J. S. Scheurer. 2005. Aggression and feeding of hatchery- and naturally-reared steelhead Oncorhynchus mykiss fry in a laboratory flume with a comparison to natural streams. Canadian Journal of Fisheries and Aquatic Sciences 62:1400-1409.

Sokal, R. R., and F. J. Rohlf. 1996. Biometry, 3rd edition. Freeman, New York.

Standen, E. M., S. G. Hinch, M. C. Healey, and A. P. Farrell. 2002. Energetic costs of migration through the Fraser River Canyon, British Columbia, in adult pink (Oncorhynchus gorbuscha) and sockeye (Oncorhynchus nerka) salmon as assessed by EMG telemetry. Canadian Journal of Fisheries and Aquatic Sciences 59:1809-1818. 